\title{
EDUCAÇÃO AMBIENTAL PARA REVEGETAÇÃO E RECUPERAÇÃO DE UMA ÁREA DEGRADADA NA RPPN CABECEIRA DO PRATA EM JARDIM (MS)
}

\author{
Marco Aurélio Lima Machado ${ }^{1}$ \\ Mayara Faleiros Quevedo ${ }^{2}$
}

Resumo: A vegetação da área que abrange a RPPN Fazenda Cabeceira do Prata sofreu intervenção antrópica ao longo do tempo, modificando sua paisagem, principalmente através da presença de gramíneas exóticas, resultado de atividades agropastoris que ocorriam antes de se tornar uma Unidade de Conservação. Com o objetivo de recuperar parte dessa área, foi feito um levantamento florístico da região e em seguida, utilizando técnicas de revegetação e conscientização por meio da Educação Ambiental, alunos da Escola Municipal Chaquib Kadri plantaram 50 mudas de 15 espécies da flora nativa. Foi utilizado o plantio heterogêneo, recriando condições ecofisiológicas mais próximas das florestas naturais, iniciando o processo de recuperação da área.

Palavras-chave: Cerrado; Unidade de Conservação; Restauração Ambiental.

\footnotetext{
1 Universidade Federal do Mato Grosso do Sul. E-mail: guiamarcoaurelio@hotmail.com

2 Universidade Federal do Mato Grosso do Sul. E-mail: mayfaleiros@hotmail.com
} 


\section{Introdução}

O Cerrado é o segundo maior bioma brasileiro, sendo superado em área apenas pela Amazônia. Ocupa 23,92\% do território nacional (IBGE) e é considerado um dos 25 locais de alta biodiversidades, de acordo com Hotspots: Hearts Biologically Richest and Most Endangered Terrestrial Ecoregions (METTERMIER et al. 1999) e um dos mais ameaçados do planeta (METTERMIER et al. 1998, MYERS et al. 2000). No estado de Mato Grosso do Sul, $65,5 \%$ de sua área é composta por vegetação de Cerrado (COSTA et. al., 2003).

As transformações ocorridas no Cerrado trouxeram grandes danos ambientais tais como: fragmentação de hábitats, extinção da biodiversidade, invasão de espécies exóticas, erosão dos solos, poluição de aquíferos, degradação de ecossistemas, alterações nos regimes de queimadas, desequilíbrios no ciclo do carbono e possivelmente modificações climáticas regionais (BRAMBILLA; PELLIN, 2006).

A região da Reserva Particular do Patrimônio Natural (RPPN) fazenda Cabeceira do Prata é localizada no município de Jardim MS, dentro do corredor de biodiversidade Miranda - Serra da Bodoquena (BRAMBILLA; PELLIN, 2006). A deliberação do Conselho Estadual de Meio Ambiente CECA-MS no. 01/1999 processo $n^{\circ} .06 / 071220 / 98$ de 20 de abril de 1999, publicado no D.O.E. no. 5005 de 27 de abril de 1999 cria a RPPN Cabeceira do Prata (Repams,associação de RPPMs do MS).

A RPPN propõe e estabelece normas a proprietários particulares que desejam ter áreas de suas propriedades preservadas como santuários de vida silvestre. Fixam mais rigidamente as condições necessárias para se tornar uma reserva particular, bem como traz a observância para assegurar a perpetuidade das espécies (BRUCK et al., 1995). Legislou esse tipo de Unidade de Conservação (UC), o artigo 1ํ do decreto ํo. 98914 de 31 de janeiro de 1990 que "dispõe sobre a instituição no território Nacional de Reservas Particulares do Patrimônio Natural por destinação do proprietário" (IBAMA, 1989).

As RPPNs exercem papel complementar importante no ordenamento territorial com vistas à reversão do atual quadro de fragmentação dos ecossistemas. Portanto, o papel das RPPNs, ao lado das reservas legais e áreas de preservação permanente, são centrais na composição de zonas tampão (entorno) de UC e no estabelecimento de corredores ecológicos entre estas e fragmentos importantes (ALGER; LIMA, 2003).

A área a ser recuperada está dentro da Zona de Recuperação definida no zoneamento ambiental quando da elaboração do Plano de Manejo da Unidade de Conservação ( $21^{\circ} 26.165^{\prime} / \mathrm{W} 056^{\circ} 25726^{\prime}$ ), região que faz parte das áreas prioritárias para a conservação de biodiversidade nos biomas do Cerrado, Pantanal e da Mata Atlântica (MMA 1999, 2000; A.N.A.2004). 
A vegetação da área caracteriza-se pelo tipo fito fisionômico savana arborizada-florestada e sofreu intervenção antrópica que ocasionou modificações em sua paisagem, principalmente através da presença de gramíneas exóticas como a Brachiaria $s p$, resultado de atividades agropastoris que ocorriam antes de se tornar uma UC (MANÇO et al., 2007).

A sucessão ecológica segundo Lopes \& Rosso, 2005, pg. 566 é o processo ordenado da instalação e desenvolvimento de uma comunidade que ocorre com o tempo e termina quando se estabelece na área uma comunidade estável (clímax). Na sucessão primária, o início da colonização ocorre em regiões anteriormente desabitadas, que não reúnem condições favoráveis à sobrevivência da grande maioria dos seres vivos, como em rochas nuas, dunas de areia recém-formadas e lavas vulcânicas recentes. $\mathrm{Na}$ sucessão secundária, o processo de mudança se verifica nos ecossistemas após a destruição parcial da comunidade. Pode ser em uma pequena área de floresta nativa, devido à queda de uma arvore, ou em vários hectares de uma cultura agropecuária abandonada (KAGEYAMA; GANDARA, 2000).

As plantas da flora arbórea brasileira podem ser reunidas em vários grupos de acordo com seu comportamento ambiental: as primárias, secundárias e as climacicas ou clímax (LORENZI, 2002, p. 14), conforme Tabela 1.

Tabela 1: Relação e características dos grupos ecológicos em diferentes estágios de sucessão Fonte: resumida de Martins (2001).

\begin{tabular}{|c|c|c|c|}
\hline \multicolumn{4}{|c|}{ Grupo Ecológico } \\
\hline Características & Primárias & Secundárias & Clímax \\
\hline Crescimento & Muito rápido & Rápido a Médio & Lento ou muito lento \\
\hline Tolerância à sombra & Muito intolerante & $\begin{array}{c}\text { Intolerante a tolerante } \\
\text { no estágio juvenil }\end{array}$ & Tolerante \\
\hline
\end{tabular}

A Educação Ambiental é considerada uma das principais ferramentas utilizadas na conservação da natureza. Segundo Nunes (2006), a Educação Ambiental revela avanços relativos em algumas áreas em especial no campo da conservação da natureza, e dos estudos da biodiversidade. Em outras abordagens, a Educação Ambiental evoluiu pouco, como é o caso da Educação Ambiental escolar, que depende exclusivamente das políticas públicas para a educação, que por sua vez dependem de decisões políticas, já que a Constituição Federal de 1988, CF 188, artigo $\S 1$ ำ diz: "promover a Educação Ambiental em todos os níveis de ensino e a constituição pública para a preservação do Meio Ambiente" (Constituição da República Federativa do Brasil, 1988).

Neste contexto, o objetivo do trabalho foi recuperar uma área que sofreu com a interferência antrópica, utilizando técnicas de revegetação na área que abrange a RPPN fazenda Cabeceira do Prata, bem como a utilização da Educação Ambiental como ferramenta para conscientização das crianças na recuperação da área degradada, fomentar a percepção dos alunos da 
importância das florestas como recurso e serviços ecológicos importantes para melhorias da qualidade de vida de toda a sociedade e também a divulgação da legislação ambiental.

\section{Materiais e Métodos}

O trabalho foi realizado na RPPN fazenda Cabeceira do Prata, localizada no município de Jardim, sudoeste de Mato Grosso do Sul, (S $21^{\circ} 27^{\prime} 54,896^{\prime \prime}$ / W $056^{\circ} 26^{\prime} 27,501$ ). Situada nos limites da região do Planalto da Bodoquena, dentro do Corredor de Biodiversidade Miranda - Serra da Bodoquena (Figura 1) (BRAMBILLA; PELLIN, 2006).

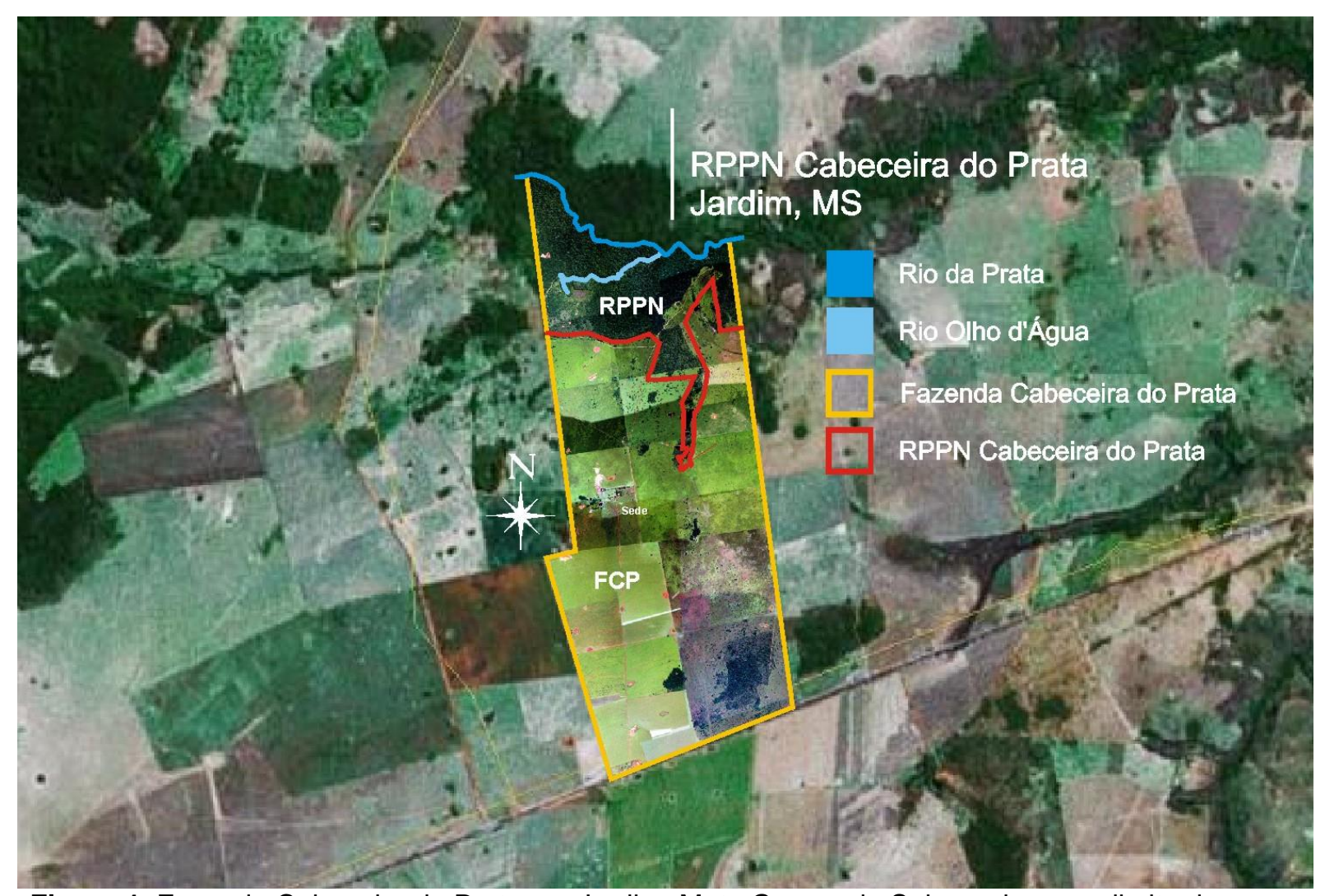

Figura 1: Fazenda Cabeceira do Prata em Jardim, Mato Grosso do Sul, sendo: rosa: limite da propriedade; verde: limite da RPPN e azul: rios da Prata e Olho d'Água. Observa-se o corredor formado pela mata ciliar do rio da Prata.

Fonte: Fotografia aérea sobre imagem Google Earth (Microsoft Company 2006)

Em 30 de março de 2011 fez se a primeira visita a campo, com a finalidade de definir a área de plantio das mudas e fazer o levantamento florístico na área que sofrera degradação devido à ação antrópica (pastagem) e em áreas próximas onde a vegetação se encontra preservada. A identificação das espécies foi feita pela observação direta (Tabela 2). 
Tabela 2: Relação das espécies de plantas utilizadas na revegetação de área na RPPN Cabeceira do Prata.

Grupos Ecológicos

\begin{tabular}{|c|c|c|c|c|c|}
\hline Plantas pioneiras & $\begin{array}{l}\text { №. de } \\
\text { mudas } \\
\text { plantas }\end{array}$ & $\begin{array}{c}\text { Plantas } \\
\text { secundárias }\end{array}$ & $\begin{array}{l}\text { №. de } \\
\text { mudas } \\
\text { plantas }\end{array}$ & Plantas clímax & $\begin{array}{l}\text { №. de } \\
\text { mudas } \\
\text { plantas }\end{array}$ \\
\hline $\begin{array}{l}\text { Jacarandá cuspidifolia } \\
\text { (carobinha) }\end{array}$ & $\begin{array}{l}03 \\
6 \%\end{array}$ & $\begin{array}{l}\text { Pseudobombax ssp } \\
\text { (paineira embiruçu) }\end{array}$ & $\begin{array}{l}02 \\
4 \%\end{array}$ & $\begin{array}{l}\text { Guibourtia } \\
\text { hymenifolia } \\
\text { (jatobá mirim) }\end{array}$ & $\begin{array}{l}02 \\
4 \%\end{array}$ \\
\hline $\begin{array}{l}\text { Cecropia } \\
\text { pachystachya } \\
\text { (embaúba) }\end{array}$ & $\begin{array}{c}05 \\
10 \%\end{array}$ & $\begin{array}{l}\text { Tabebuia róseo alba } \\
\text { (ipê branco) }\end{array}$ & $\begin{array}{l}02 \\
4 \%\end{array}$ & $\begin{array}{l}\text { Aspidosperma } \\
\text { ramiflorum } \\
\text { (guatambu) }\end{array}$ & $\begin{array}{l}02 \\
4 \%\end{array}$ \\
\hline $\begin{array}{l}\text { Guazuma ulmifolia } \\
\text { (chico-magro ou } \\
\text { mutambo) }\end{array}$ & $\begin{array}{c}08 \\
16 \%\end{array}$ & $\begin{array}{l}\text { Platipodium elegans } \\
\text { (Amendoim do } \\
\text { campo) }\end{array}$ & $\begin{array}{c}05 \\
10 \%\end{array}$ & $\begin{array}{l}\text { Aspidosperma } \\
\text { polyneuron } \\
\text { (Peroba rosa) }\end{array}$ & $\begin{array}{l}02 \\
4 \%\end{array}$ \\
\hline $\begin{array}{l}\text { Anadenanthera } \\
\text { macrocarpa (angico } \\
\text { vermelho) }\end{array}$ & $\begin{array}{l}04 \\
8 \%\end{array}$ & $\begin{array}{l}\text { Talisia esculenta } \\
\text { (Pitomba). }\end{array}$ & $\begin{array}{l}02 \\
4 \%\end{array}$ & $\begin{array}{l}\text { Hyrimenea } \\
\text { stigonocarpa } \\
\text { (jatobá do } \\
\text { cerrado) }\end{array}$ & $\begin{array}{l}02 \\
4 \%\end{array}$ \\
\hline $\begin{array}{l}\text { Lithraea molleoides } \\
\text { (Aroeirinha) }\end{array}$ & $\begin{array}{l}04 \\
8 \%\end{array}$ & & & & \\
\hline $\begin{array}{l}\text { Peltophorum dubium } \\
\text { (Canafistula) }\end{array}$ & $\begin{array}{l}03 \\
6 \% \\
\end{array}$ & & & & \\
\hline $\begin{array}{l}\text { Peschiera fuchsiaefolia } \\
\text { (Leiteira) }\end{array}$ & $\begin{array}{l}04 \\
8 \%\end{array}$ & & & & \\
\hline
\end{tabular}

Fonte: Lorenzi (2002)

Com a chegada das chuvas no início de setembro, o local destinado ao plantio das mudas foi preparado, com o estaqueamento (fixação das estacas) e no dia 15 de setembro foi feito coroamento. Já na véspera do plantio, dia 03 de outubro foi feito o coveamento para receber as mudas.

Participaram do plantio de mudas e da palestra 32 alunos do $5^{\circ}$ ao $8^{\circ}$ ano e 04 professores da Escola Municipal Chaquib Kadri de Jardim MS. Os alunos e professores chegaram na fazenda no dia 04 de outubro, onde foram recebidos e apresentados às instalações (banheiros, bebedouros, etc.) e em seguida, encaminhados para o local da palestra.

Iniciou-se a palestra esclarecendo sobre as atividades sustentáveis desenvolvidas na fazenda, como ecoturismo e sistema silvipastoril, os biomas brasileiros e suas características também foram mencionados, enfatizando o bioma Cerrado. Informações para preservação do Meio Ambiente, sobre como identificar áreas degradadas e como recuperá-las também foram desenvolvidos com os participantes. Além disso, assuntos como viveiro de mudas, sementário, compostagem, minhocário e horta orgânica foram abordados.

No local da palestra foi feito um plantio modelo, para que os alunos pudessem reproduzir a técnica a campo (Figura 2). 


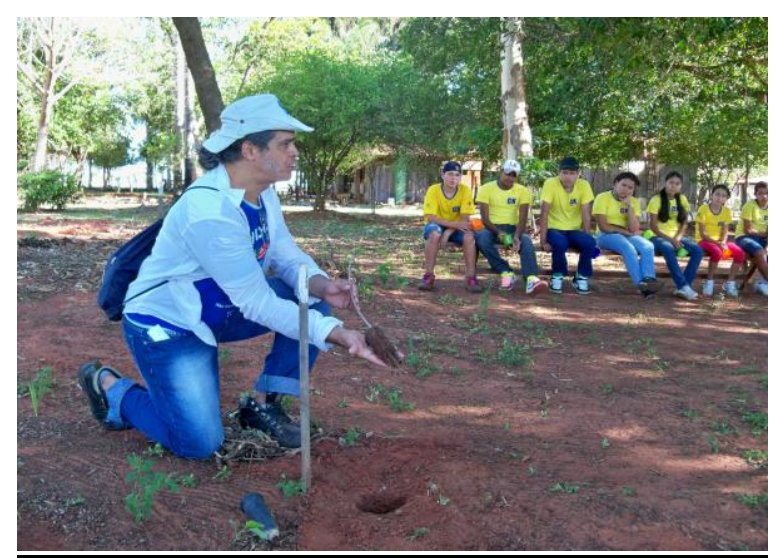

Figura 2: Plantio modelo de uma muda para facilitar o trabalho dos alunos em campo.

Seguiu-se por uma trilha de cerca de 150 metros, passando pelo viveiro de mudas onde os alunos puderam observar e identificar as espécies distintas ali presente, explicando sobre grupos ecológicos, primarias, secundarias e clímax. Na sequência, foram encaminhados para o local de compostagem, onde os alunos receberam noções de como fazer uma composteira. Logo, seguiu-se para o sementário onde foi possível explicar alguns tipos de dispersão de sementes, como zoocoria, anemocoria e por último, foi abordado a horta orgânica e o minhocario.

Os 32 alunos e os 04 professores formaram 12 grupos de três participantes cada, para facilitar o plantio. Deslocaram-se da sede da fazenda até a RPPN, local do plantio, em 02 camionetes da própria fazenda, em dois grupos de 18 participantes.

Para o reflorestamento foi utilizado o plantio heterogêneo, que consiste no plantio conjunto de diferentes espécies numa mesma área. O modelo implantado procurou contemplar todos os estádios de sucessão simultaneamente, no ato do plantio.

Todas as mudas são oriundas do viveiro de mudas nativas da própria RPPN, as mudas tinham um tamanho médio de $40 \mathrm{~cm}$.

$\mathrm{Na}$ preparação do terreno, foi utilizada estaca de $1 \mathrm{~m}$ de comprimento para a marcação do local. Para o coroamento, retirou-se o capim em torno da estaca com aproximadamente $1,5 \mathrm{~m}$ de diâmetro, deixando a terra exposta. No coveamento, cavou-se um buraco de $20 \mathrm{~cm}$ de profundidade para o plantio da muda. O capim extraído do coroamento foi colocado ao redor das mudas que foram plantadas, para garantir a umidade no solo.

Os modelos de restauração se restringem, portanto, à definição e à interpretação dos grupos ecológicos e da forma de se usar e associar as plantas desses grupos no plantio (KAGEYAMA; GANDARA, 2000).

Os alunos plantaram um total de 50 mudas nativas, distribuídas em 15 espécies sendo utilizadas espécies primárias, secundárias e clímax numa proporção de $62 \%$, 22\% e 16\% respectivamente, plantadas em uma única 
etapa, tomando sempre o cuidado de alocar as mudas de espécies clímax próximas de dois ou mais exemplares de espécies pioneiras e secundárias. As espécies utilizadas no plantio estão relacionadas conforme a Tabela 2.

Há necessidade de monitoramento periódico das mudas em campo durante um período de 2 anos, coletando dados sobre altura da muda e diâmetro do caule, bem como da manutenção do coroamento/capina no entorno da muda.

\section{Resultados e Discussão}

No levantamento florístico da região, pode ser observada a presença de espécies arbóreas e arbustivas em diferentes fases de crescimento (Tabela 3) o que facilitou na escolha das espécies a serem plantadas, possibilitando assim a continuidade da sucessão ecológica na região.

Tabela 3: Espécies de árvores encontradas na região da RPPN Cabeceira do Prata, localizada no município de Jardim MS.

\begin{tabular}{|c|c|c|c|}
\hline FAMILIA & NOME CIENTÍFICO & NOME POPULAR & $\begin{array}{c}\text { GRUPO } \\
\text { ECOLÓGICO }\end{array}$ \\
\hline ANACARDIACEAE & $\begin{array}{c}\text { Myracrodruon urundeuva } \\
\text { Lithraea molleoides }\end{array}$ & $\begin{array}{c}\text { aroeira } \\
\text { aroeirinha }\end{array}$ & $\begin{array}{l}\text { clímax } \\
\text { primária }\end{array}$ \\
\hline ANNONACEAE & Rollinia emarginata & ariticum-do-mato & secundária \\
\hline APOCYNACEAE & $\begin{array}{l}\text { Peschiera fuchsiaefolia } \\
\text { Aspidosperma ramiflorum } \\
\text { Aspidosperma polyneuron }\end{array}$ & $\begin{array}{c}\text { leiteira } \\
\text { guatambu } \\
\text { peroba rosa }\end{array}$ & $\begin{array}{l}\text { primária } \\
\text { clímax } \\
\text { clímax }\end{array}$ \\
\hline BIGNONIACEAE & $\begin{array}{l}\text { Tabebuia impetiginosa } \\
\text { Tabebuia áurea } \\
\text { Tabebuia róseo auba } \\
\text { Tabebuia ssp } \\
\text { Jacarandá cuspidifolia }\end{array}$ & $\begin{array}{l}\text { piúva-da-mata } \\
\text { para tudo } \\
\text { lpê branco } \\
\text { ipê do cerrado } \\
\text { carobinha } \\
\end{array}$ & $\begin{array}{l}\text { secundária } \\
\text { secundária } \\
\text { secundária } \\
\text { secundária } \\
\text { secundária }\end{array}$ \\
\hline BOMBACACEAE & Pseudobombax ssp & imbiruçu & secundária \\
\hline CARICACEAE & Jaracatiá spinosa & jaracatiã & primária \\
\hline CECROPIACEAE & Cecropia pachystachya & embaúba & primária \\
\hline COMBRETACEAE & $\begin{array}{l}\text { Combretum leprosum } \\
\text { Terminalia argetea }\end{array}$ & $\begin{array}{c}\text { carne-de-vaca } \\
\text { capitão do campo }\end{array}$ & $\begin{array}{l}\text { secundária } \\
\text { secundária }\end{array}$ \\
\hline EUPHORBIACEAE & Sapium haematospermum & leiteira & primária \\
\hline HIPPOCRATEACEAE & Salacea elliptica & seputá & secundária \\
\hline $\begin{array}{l}\text { LEGUMINOSAE- } \\
\text { CAESALPINOIDEAE }\end{array}$ & $\begin{array}{l}\text { Guibourtia hymenifolia } \\
\text { Pterogyne nitens } \\
\\
\text { Bauhinia forficata } \\
\text { Peltophum dubium } \\
\text { Dimorphandra mollis } \\
\text { Hyrimenea stigonocarpa }\end{array}$ & $\begin{array}{l}\text { jatobá-mirim } \\
\text { amendoim-do- } \\
\text { cerrado } \\
\text { pata de vaca } \\
\text { canafistula } \\
\text { faveira } \\
\text { jatobá do cerrado }\end{array}$ & $\begin{array}{l}\text { clímax } \\
\text { secundária } \\
\text { primária } \\
\text { primária } \\
\text { primária } \\
\text { clímax }\end{array}$ \\
\hline
\end{tabular}

Continua... 
...continuação.

\begin{tabular}{|c|c|c|c|}
\hline FAMILIA & NOME CIENTÍFICO & NOME POPULAR & $\begin{array}{c}\text { GRUPO } \\
\text { ECOLÓGICO }\end{array}$ \\
\hline $\begin{array}{c}\text { LEGUMINOSAE- } \\
\text { MIMOSOIDEAE }\end{array}$ & $\begin{array}{c}\text { Anadenanthera macrocarpa } \\
\text { Enterolobium } \\
\text { contorticiliquum } \\
\text { Inga vera }\end{array}$ & $\begin{array}{c}\text { angico-vermelho } \\
\text { ximbuva } \\
\text { ingá }\end{array}$ & $\begin{array}{c}\text { primária } \\
\text { primária } \\
\text { primária }\end{array}$ \\
\hline $\begin{array}{c}\text { LEGUMINOSAE- } \\
\text { PAPILIONOIDEAE } \\
\text { (FABACEAE) }\end{array}$ & $\begin{array}{c}\text { Platipodium elegans } \\
\text { MORACEAE }\end{array}$ & $\begin{array}{c}\text { Amendoim do } \\
\text { campo }\end{array}$ & secundária \\
\hline MYRSINACEAE & Rapanea gardneriana & pororoca & primária \\
\hline PALMAE & Acrocomia aculeata & bocaiúva & primária \\
\hline PHYLOLACCEAE & Phytolacca dioíca & cebolão & secundária \\
\hline RHAMNACEAE & Zizyphus itacaiunensis & maria preta & secundária \\
\hline SAPINDACEAE & Talisia esculenta & pitomba & secundária \\
\hline STERCULIACEAE & Guazuma ulmifolia & $\begin{array}{c}\text { chico-magro ou } \\
\text { mutambo } \\
\text { mandovi }\end{array}$ & primária \\
VERBENACEAE & Sterculia apétala & tarumã & secundária \\
\hline VOCHYSIACEAE & Qualex Cymosa grandiflora & pau terra & primária \\
\hline
\end{tabular}

Fonte: próprio autor.

O plantio heterogêneo recriou condições ecofisiológicas mais próximas das condições encontradas nas florestas naturais. O método utilizado neste trabalho visou acelerar os processos naturais de recomposição florestal. As mudas de espécies clímax foram colocadas próximas de dois ou mais exemplares de espécies pioneiras e secundárias, pois estas crescem rapidamente proporcionando 0 sombreamento necessário para 0 estabelecimento das espécies clímax. (LORENZI, 2002)

O plantio das mudas ocorrera nos meses em que exista expectativa de chuvas, facilitando assim a "pega" das mudas. Caso isto não ocorresse, haveria necessidade de se proceder com a irrigação (BARBOSA, 2000).

A experiência prática tem mostrado que todas as categorias de plantas (pioneiras, secundarias, clímax), podem ser implantadas numa única etapa.

Baseado em observação de campo e nos diferentes trabalhos já realizados (COSTA et al., 1992; GONÇALVES et al., 1992; ALMEIDA, 1996), pode se agrupar as espécies pertencentes aos diferentes grupos ecofisiológicas de conformidade com as características próprias (ALMEIDA, 2000 p. 34).

A restauração de ecossistemas degradados deve seguir o princípio de que as espécies nativas do local são as que têm maior probabilidade de se desenvolver plenamente, mantendo suas características de reprodução e de regeneração natural, em equilíbrio com seus organismos predadores naturais (KAGEYAMA, GANDARA, 2000). 
O plantio de essências nativas acelera o processo de sucessão secundária, reduzindo o tempo para a formação de uma mata densa semelhante a natural para apenas 10-15 anos (LORENZI, 2002, p. 15).

Cobriu-se o solo onde foi plantada a muda com o capim extraído do coroamento, já que em áreas onde a aplicação de herbicida pode comprometer o sistema, o custo de recuperação torna-se elevado devido às despesas de manutenção, podendo se neste caso utilizar a matéria orgânica morta, ao redor das mudas. A camada orgânica colocada ao redor das mudas (coroa) garante a umidade do solo e evita o surgimento de plantas competidoras com as que foram implantadas.

Em ambientes altamente degradados, os solos sofreram processo intensivo de degradação, que exigem a intervenção humana para sua recuperação. Em geral, em áreas com utilização antrópica (agropecuária), as alterações são de grande intensidade. Assim, sua recuperação dificilmente traria de volta o ecossistema inicial, com toda sua estrutura comunitária e sua biodiversidade. É comum ocorrer à extinção local de algumas espécies, como mamíferos, aves e microorganismos, impossibilitando a retomada da dinâmica natural de origem (RIBEIRO et al., 2001 pg. 817 e 818).

Durante a atividade de plantio das árvores pode-se constatar a presença de vestígios de fauna (pegadas) na área do plantio, tais como: Lobinho (Dusicyon thous), Catetos (Tayassu tajacu) e Queixadas (Tayassu albitrostris) e até mesmo o maior mamífero terrestre do Brasil, a Anta (Tapirus terrestris), de aves como a Ema (Rhea americana) e a Seriema (Cariama cristata). Por meio desses indícios, pode-se inferir que as interações ecológicas vêm ocorrendo no local, o que proporciona melhores condições ambientais para a recuperação da área.

Conforme Kageyama e Gandara (2000, p. 253 e 254), apesar do termo restauração se referir à reintrodução de plantas, não se pode esquecer da fauna desse ecossistema principalmente quando o objetivo fundamental é a restauração do ecossistema original. A interação entre plantas e animais em florestas tropicais é muito intensa, sendo determinante para a estruturação do ecossistema, pois se trata de relações fundamentais, como polinização, dispersão de sementes e herbivoria predação.

A manutenção do coroamento/capina no entorno da muda é necessária para que não ocorra o abafamento dela. Essa manutenção e monitoramento adequado das mudas no campo, bem como a proximidade da área sob revegetação com outros fragmentos florestais próximos e da presença de dispersores presentes podem acelerar a ligação da dinâmica natural, das constantes renovações dos ciclos de crescimento e da sucessão natural das espécies ocorrentes no local.

Em campo os alunos tiveram a oportunidade não só de conhecer várias espécies de árvores, mas também aprender técnicas de plantio, ajudando assim a reflorestar as áreas em recuperação da RPPN Cabeceira do Prata. 
Ao final do plantio, pode-se perceber através da satisfação e interesse dos alunos durante a atividade, que a Educação Ambiental utilizada como ferramenta para recuperação de áreas degradadas é de extrema importância para o coletivo das comunidades locais sobre o papel delas enquanto atores sociais, seres atuantes e responsáveis pelo ambiente como um todo. As atividades de Educação Ambiental despertaram grande interesse nos alunos, pois permitiu a saída da "rotina" da sala de aula. Alguns alunos são moradores de área rural e foram mais participativos, apresentando sugestões e permanecendo atentos às questões ambientais propostas, pela convivência direta com meio ambiente.

\section{Considerações finais}

A conscientização sobre a necessidade de conservação e defesa do Meio Ambiente é evidente tanto para a geração atual quanto para as futuras gerações, uma vez que possibilita novas posturas e melhor relacionamento com o meio, aquisição de conhecimentos e participação ativa nas atividades para preservação e a conservação promove atitudes de respeito nas interrelações dos seres humanos com a natureza.

A manutenção e o acompanhamento técnico eficiente associado às atividades de Educação Ambiental necessitam de ações efetivas para que os conceitos e conhecimentos sejam construídos entre os alunos e consequentemente trabalhado na comunidade. Neste contexto o desenvolvimento desta pesquisa poderá contribuir de forma que os alunos realizem a disseminação do saber construído com ideias e ações de preservação e conservação visando melhoria ambiental e qualidade de vida.

\section{Referências}

ALGER, K.; LIMA, A. Políticas Públicas e a Fragmentação de Ecossistemas. In: RAMBALDI, D.M.; OLIVEIRA, D.A.S. (orgs) Fragmentação de ecossistemas: causas e efeitos sobre a biodiversidade e recomendação para políticas públicas / Brasília: MMA/SBF: 510p. 2003.

ALMEIDA, S.P. et al., Cerrado: Espécies Vegetais Úteis. Planaltina. Embrapa. 1998.

ALMEIDA. D. S. Recuperação Ambiental da Mata Atlântica. Ed. Aditus. llhéus. 2000.

A.N.A. Agência Nacional das Águas. 2004.

BARBOSA, L.M. Considerações Gerais e Modelos de Recuperação de Matas Ciliares. In: RODRIGUES, R.R. e LEITÃO, H. F., Mata Ciliares - Conservação e Recuperação. São Paulo Ed. USP/FAPESP. Pp.289-311. 2000. 
BARBOSA, L.M. Recuperação de Áreas Degradadas da Serra do Mar e Formações Florestais Litorâneas. Secretária de Estado de Meio Ambiente. São Paulo: 139 p. workshop 2000.

BRAMBILLA, M.; PELLIN, A. Projeto Corredor de Biodiversidade Miranda Serra da Bodoquena: Ações Prioritárias do Plano de Conservação e Implementação. Relatório Fundação Neotrópica do Brasil e Conservação Internacional do Brasil. Campo Grande: 434p. 2006.

BRASIL. Ministério do Meio Ambiente. Diretoria do Programa Nacional de Conservação da Biodiversidade - DCBIO. Brasília: 347p. 2004.

BRASIL, Constituição da República Federativa do Brasil, de 05 de outubro de 1988.

BRUCK, E.C. Unidades de Conservação no Brasil-Cadastramento e Vegetação. 1991-1994. Relatório Síntese. IBAMA. Brasília: 225p. 1995.

COSTA. R.B.; SCARIOT, A. A Fragmentação Florestal e seus Recursos Genéticos. Fragmentação e Alternativas do Desenvolvimento rural na Região Centro-Oeste. UCDB. Campo Grande. 2003.

Escola Municipal Chaquib Kadri. Rua Márcia Valéria de Freitas, №1335. Bairro: vila SEAC, Jardim/MS.

IBAMA. Instituto Brasileiro do Meio Ambiente e dos Recursos Naturais Renováveis. Unidades de Conservação do Brasil. Vol. 1- Parques Nacionais e Reservas Biológicas. Brasília. 1989.

IBAMA. Instituto Brasileiro do Meio Ambiente e dos Recursos Naturais Renováveis. Unidades de Conservação do Brasil: Parques Nacionais e Reservas Biológicas. Brasília: 182p. 1989.

IBAMA. Instituto Brasileiro do Meio Ambiente e dos Recursos Naturais Renováveis. Diretória de Recursos Naturais Renováveis. Brasília. 1990.

KAGEYAMA, P.; GANDARA, F.B. Recuperação de Áreas Ciliares. São Paulo: Pp. 253-254. 2000.

KAGEYAMA, P.; GANDARA, F.B. Restauração e Conservação de Ecossistemas Tropicais. Universidade de São Paulo (USP). São Paulo: Pp. 383-393. 2000.

LOPES, S.; ROSSO, S. Biologia. 1a. ed. São Paulo. Ed. Saraiva. 2005.

LORENZI, H. Árvores Brasileiras - Manual de Identificação e Cultivo de Plantas Arbóreas Nativas do Brasil. 4aㅡ ed.v.1. Nova Odessa. Ed., Instituto Plantarum. 2002.

LORENZI, H. Árvores Brasileiras - Manual de Identificação e Cultivo de Plantas Arbóreas Nativas do Brasil. 2 $2^{\underline{a}}$ ed. v.2. Nova Odessa. Ed. Instituto Plantarum. 2002. 
MANÇO, D.G., et al. Plano de Manejo RPPN Cabeceira do Prata. Jardim. 2007.

MARTINS, S. V. Recuperação de Mata Ciliares. Viçosa. Ed. Aprenda Fácil. 143p. 2001.

MATO GROSSO DO SUL. Deliberação CECA/MS n‥001-99, processo ํo.06/071 220/98, de 20 de abril de 1999, Reconhecimento de Reserva Particular do Patrimônio Natural. Diário Oficial do Estado do Mato Grosso do Sul, Campo Grande, ano XXI n.5005, p 03,24p.27 de abril de 1999.

MINISTÉRIO DO MEIO AMBIENTE (MMA). Ações Prioritárias para a Conservação da Biodiversidade do Cerrado e Pantanal. Brasília. 1999.

MINISTÉRIO DO MEIO AMBIENTE (MMA). Avaliação e Ações Prioritárias para a Conservação da Biodiversidade da Mata Atlântica e Campos Sulinos. Brasília: 40p. 2000.

MITTERMEIER, R. A.; MYERS, N.; MITTERMEIER, C .G. Hotspots: Hearts Biologically Richest and Most Endangered Terrestrial Ecoregions. New York: CEMEX. Conservation International. In: PAGOTTO, T.C.S.; SOUZA, P.R. (ORG). Biodiversidade do Complexo Aporé-Sucuriú: Subsídios à Conservação e Manejo do Bioma Cerrado. Ed. UFMS. Campo Grande: 308p. 2006.

NUNES, E.R.M., Preservação e Conservação da Natureza via Consciência Ecológica e Cidadania Ambiental: qual o papel da educação ambiental. Caxias do Sul. 2006.

RIBEIRO, J. F., et al., Cerrado: Caracterização e Recuperação de Matas de Galeria. Embrapa/cerrados, Planaltina:.899p. 2001. 